\title{
Economic Emission Dispatch in Renewable Energy Systems using FireFly Algorithm
}

\section{Chithra S}

Department of Electronics and Communication Engineering, University College of Engineering Nagercoil

Nagercoil, Tamil Nadu, India

rs chithra.19@gmail.com

\author{
Madhana Kumarai R \\ Department of Computer Science and Engineering, \\ Zeal College of Engineering and Research \\ Pune, Maharashtra, India \\ Madhanaraman55@gmail.com
}

\begin{abstract}
In the upcoming developments, the optimal Economic Emission Dispatch (EED) is necessitated by the power system owing to the addition of power generation cost and ever growing requirement of electrical energy. Therefore, the minimization of power generation cost with respect to emission cost and fuel cost has turn out to be one of the major drawbacks in power system. Consequently, this paper implements FireFly (FF) algorithm to offer the best optimal solution for the issues concerning Combined Economic and Emission Dispatch (CEED). Also, the suggested algorithm is executed in seven Hybrid Renewable Energy Systems (HRES) test bus systems that unites the wind turbine together with the thermal power plant. Moreover, the proposed FF-HRES scheme is compared with traditional algorithms such as Simulated Annealing (SA) and Differential Evolution (DE) schemes and the results are obtained.
\end{abstract}

Keywords: Emission Dispatch; Combined Economic and Emission Dispatch; FireFly; Fuel cost; Emission cost.

\section{Introduction}

The EED is to search for the best possible schedule of power generators for reducing the entire cost of fuel and provide the challenging load plus transmission loss, gratifying generator power restrictions and functioning restraints [1] [2]. Based on fossil fuels, several toxic gases are released by the thermal power plants that will do destruction to lives on earth [3]. In addition, it influences the increase of temperature worldwide. With the rising that concerns on friendly atmosphere, the companies generating power are essential to control the discharge of contaminants that has been strained to control the level of emission beneath particular restraints [4] [5]. Economic Emission Dispatch (EED) intends to control the cost of generation and lessen the influence of ravage gas on the atmosphere, when the emission cost and fuel generation cost disagree with each other. Owing to the complex VPE and constraints [6] [7], it is uncomplicated to contract with EED dilemma. The sub regions of disjoint convex separated by Prohibited Operating Zones (POZs) directs to discontinuities among the fuel cost and the power output of Generation Units (GUs) [8]. In addition, valve point effect (VPE) show the way to numerous local minimums with non-convex characteristics in intended operations, thus it is a challenge assignment to explore for global minimum [9] [10].

The EED crisis has multiple constraints and non-convex objectives while taking into account of VPN. Conventional schemes do not succeed to manage with this crisis owing to its complication. For solving EED crisis, there primarily subsist two kinds of optimization equipments suggested in numerous researches in the last two decades [11] [12].

Moreover, the thermal power plants depending on fossil fuels discharges noteworthy quantity of destructive pollutants like oxides of nitrogen, carbon and sulphur that not only influences, human, plant and animal's lives but in addition contribute for disquieting global warming. This has strained the electric utilities to lessen the plant emission level underneath particular restrictions all over the world [13] [14]. Consequently, EED is a striking substitute in which both minimization of pollutant and emission economy of fuel cost are managed simultaneously, even if the emission and cost functions are of contradictory character [15]. The EED crisis turns out to be more multifaceted owing to the practical 
restraints like POZs, ramp rate limits and VPE [16] [17]. The POZs influences discontinuities of cost in higher order nonlinear function. In addition, the VPE causes non-convex feature with multiple minima and therefore inflicts challenges to attain the global optima. Owing to the complication of the issue, traditional techniques such as Lagrange relaxation process and gradient scheme are not appropriate. The dynamic programming can resolve such kinds of issues; however it endures from the annoyance of dimensionality [18]. For the past two decades, modern stochastic dependent meta-heuristic methods have attained more consideration by the researchers owing to their capability to attain near global or global solution. Numerous swarm and evolutionary dependent computational methods have been tried out EED issues such as Genetic Algorithm (GA) has corresponding search abilities that emulate natural genetic operations. However, it has reduced implementation speed [19] and could not guarantee constant optimization [20].

This paper contributes a solution for the minimization of fuel cost and emission cost of HRES power systems by means of FF algorithm. Moreover, the proposed method is distinguished with conventional algorithms such as SA and DE and the corresponding results are attained. This paper is organized as follows. Section 2 explains the related works and reviews done under this topic. Moreover, section 3 analyses the modelling of CEED systems and section 4 portrays the results and discussions. Finally, section 5 concludes the paper.

\section{Literature Review}

\subsection{Related Works}

In 2017, Karl et al. [1] has suggested a number of PSO variants to the Dynamic Economic Emission Dispatch (DEED) crisis. The DEED dilemma is a multi-objective optimisation crisis in which the objective was to optimise two contradictory intentions, namely, emissions and cost. The PSO variants that were tested consist of the PSO with Avoidance of Worst Locations (PSO AWL), and in addition a selection of diverse topologies as well as the PSO along with Gradually Increasing Directed Neighbourhood (PSO GIDN) .The consequences demonstrates that the PSO AWL offers better results than the SPSO for each implemented topology. The outcomes were further distinguished with MultiAgent Reinforcement Learning (MARL) and conventional Genetic Algorithm (NSGA-II) and the improved results were obtained.

In 2017, Tiancai et al. [2] proposed a Collective Neurodynamic Optimization (CNO) system that merges Projection Neural Network (PNN) and heuristic technique, which was effort to optimize setting up of an electrical microgrid together with 10 thermal generators and reduce the plus of emission and generation expenditure. As the intention has non-derivative points taking into account of VPE, differential inclusion scheme was adopted in the PNN design which was established to manage with them. In particular circumstances, the local convergence and optimality of the dynamic design for the optimization crisis was scrutinized. The potential of the technique was established in a complex condition, in which banned operating zones and transmission loss were measured. Moreover, the dynamic distinction of load power at demand side was regarded and the best possible setting up of generators within a day was defined.

In 2015, Vinay Kumar et al. [3] has implemented a Modulated Particle Swarm Optimization (MPSO) process to resolve the EED crisis occurring in thermal units. The traditional PSO was customized by adapting velocity of particles for improved exploitation and exploration of the search space. The velocity of particles modulation was regulated by establishing a condensed sinusoidal constraint function in PSO. The contradictory objectives of the EED crisis were implemented in fuzzy framework by signifying accustomed fuzzy membership functions that were subsequently optimized by means of implemented PSO. The efficiency of the suggested PSO was verified on three standard test systems in view of numerous functioning constraints such as Prohibited Operating Zones (POZs), and valve point consequence. The outcomes of application and their assessment with erstwhile conventional methods demonstrate that the implemented MPSO was capable for solving EED crisis of thermal generating units.

In 2016, Abhishek et al. [4] has introduced an Optimum Active Power Dispatch (OAPD) crisis by means of a most currently established optimizer known as 'Exchange Market Algorithm' (EMA). The crisis was designed as both multi-objective and single-objective issue. The EMA technique continues for the global optima by means of its two major phases, namely, oscillated market phase and balance market phase, all including both exploration and exploitation. The advanced search capacity of EMA was effectively utilized in this paper to accomplish different objectives. Programs were executed in MATLAB and verified on standard IEEE 30 bus encompassing of six thermal units. The outcomes attained by 
means of EMA were distinguished with various schemes detailed in the presented paper. Simulation outcomes reveal the ability of EMA regarding its computational robustness and effectiveness.

In 2016, Abdelaziz et al. [5] has implemented a Flower Pollination Algorithm (FPA) to resolve Economic Load Dispatch (ELD) and Combined CEED inconveniences in power systems. An evaluation of the computed results by means of the suggested FPA was executed to substantiate its efficiency in opposition to various swarm intelligent algorithms for six diverse power systems. The dominance of the implemented FPA distinguished with various algorithms was illustrated even for power systems at large scale taking into account of VPE.

\subsection{Review}

Table 1 shows the methods, features and challenges of conventional techniques based on emission dispatching techniques. At first, PSO algorithm was implemented in [1] that offers better convergence speed and is able to optimise constrained problem. However, there was no contemplation on diverse set of Pareto Optimal solutions for DEED. In addition, Collective Neuro dynamic Optimization was suggested in [2] that controls generation cost and lessens the impact of waste gas in the atmosphere, but the cost increases with increase in load demand. In addition, MPSO algorithm was proposed in [3] that facilitate to explore wider search areas with higher average fitness. Anyhow, it may get trapped in local optima owing to premature convergence. In addition, Exchange Market Algorithm (EMA) was presented in [4] that solve Optimum Active Power Dispatch issue (OAPD). It also offers better robustness and computational effectiveness. However, it involves certain risk in choosing shares for trading. Finally, Flower Pollination Algorithm (FPA) was proposed in [5] that resolves complicated issues in power systems with minimized complexity, but there was no contemplation on multi-area power system with wind farms and PV system. These above mentioned challenges are considered for motivating the improvement of EED.

Table 1. Review on the state of art Economic Dispatch methods

\begin{tabular}{|c|c|c|c|}
\hline $\begin{array}{l}\text { Author } \\
\text { [citation] }\end{array}$ & $\begin{array}{l}\text { Adopted } \\
\text { methodology }\end{array}$ & Features & Challenges \\
\hline Karl et al. [1] & PSO algorithm & $\begin{array}{l}* \text { Offers better convergence speed } \\
* \text { Able to optimise constrained problem }\end{array}$ & $\begin{array}{l}\text { * No contemplation on diverse set of } \\
\text { Pareto Optimal solutions for DEED }\end{array}$ \\
\hline $\begin{array}{l}\text { Tiancai et } a l \text {. } \\
\text { [2] }\end{array}$ & $\begin{array}{l}\text { Collective } \\
\text { Neurodynamic } \\
\text { Optimization }\end{array}$ & $\begin{array}{l}\text { * Controls generation cost } \\
\text { Lessens the impact of waste gas on the } \\
\text { atmosphere }\end{array}$ & $\begin{array}{l}\text { * Cost increases with increase in load } \\
\text { demand. }\end{array}$ \\
\hline $\begin{array}{l}\text { Vinay Kumar } \\
\text { et } a l . \text { [3] }\end{array}$ & MPSO algorithm & $\begin{array}{l}\text { Facilitates to explore wider search areas } \\
\text { * Higher average fitness }\end{array}$ & $\begin{array}{l}\text { * May get trapped in local optima owing to } \\
\text { premature convergence }\end{array}$ \\
\hline $\begin{array}{l}\text { Abhishek et } \\
\text { al. [4] }\end{array}$ & EMA & $\begin{array}{l}\text { * Solves Optimum Active Power Dispatch } \\
\text { issue } \\
\text { * Better robustness and computational } \\
\text { effectiveness }\end{array}$ & $\begin{array}{l}\text { Involves certain risk in } \\
\text { choosing shares for trading }\end{array}$ \\
\hline $\begin{array}{l}\text { Abdelaziz et } \\
\text { al. }[5]\end{array}$ & FPA & $\begin{array}{l}\text { * Resolves complicated issues in power } \\
\text { systems } \\
\text { * Reduced complexity }\end{array}$ & $\begin{array}{l}\text { * No contemplation on multi-area power } \\
\text { system with wind farms and PV system. }\end{array}$ \\
\hline
\end{tabular}

\section{CEED System Model}

Assume a HRES power generation system that comprises of solar energy and wind turbine systems. In this paper, the entire solar system is predicted to be $S$ and wind turbine is considered to be T. Fundamentally, the entire energy produced from the solar system $\mathrm{P}^{\mathrm{gm}}$ is dependent on the solar intensity, and produced power is with in the minimum and maximum values. Therefore, design of the produced power is given by Eq. (1) in which $\mathrm{m}=1,2, \ldots \mathrm{S}, \lambda^{\mathrm{m}}$ indicates the effectiveness of the system, $\mathrm{a}^{\mathrm{m}}$ refers the region of the system and $D(t)$ denotes the solar intensity. Similarly, the entire energy from the wind turbine $e^{w}$ is given by Eq. (2) that is dependent on the velocity of the turbine in various areas. In Eq. (2), $\mathrm{w}=1,2, \ldots \mathrm{T}, \mathrm{P}_{0}$ indicates the atmospheric pressure of the standard sea level $(101325 \mathrm{~Pa})$, a signifies the swept region, $\mathrm{k}^{\mathrm{p}}$ symbolizes the power coefficient of wind turbine, $g_{k}$ point out the specific gas constant of air $(287 \mathrm{~J} /(\mathrm{kg} . \mathrm{K})), \mathrm{V}_{\mathrm{w}}$ denotes the wind turbine velocity, $\mathrm{G}$ denotes the gravitational constant, A point out the altitude in metres, $t$ symbolizes the temperature in Kelvin as $\mathrm{t}=\mathrm{t}_{0}-\mathrm{RA}$ in 
which $\mathrm{t}_{0}$ correspond to the sea level temperature (288K) and $R$ represents the temperature lapse rate $\left(0.0065^{\circ} \mathrm{C} / \mathrm{m}\right)$.

$$
\begin{aligned}
& \mathrm{P}^{\mathrm{gm}}=\lambda^{\mathrm{m}} \mathrm{a}^{\mathrm{m}} \mathrm{D}(\mathrm{t}) \\
& \mathrm{e}^{\mathrm{w}}=\sum_{\mathrm{w}=1}^{\mathrm{T}} \frac{\mathrm{P}_{0} \mathrm{aV}_{\mathrm{w}}^{3} \mathrm{k}^{\mathrm{p}}}{2 \mathrm{~g}_{\mathrm{k}} \mathrm{t}} \mathrm{e}^{\frac{\mathrm{GA}}{\mathrm{g}_{\mathrm{k}} \mathrm{t}}}
\end{aligned}
$$

Economic Model: The integration of the quadratic function produces the entire cost function of the fuel $\mathrm{F}\left(\mathrm{P}^{\mathrm{gm}}\right)$ that is indicated by Eq. (3) in which $\mathrm{P}^{\mathrm{gm}}$ point out the power production of $\mathrm{m}^{\text {th }}$ generating unit, $\mathrm{K}^{\mathrm{m}}, \mathrm{L}^{\mathrm{m}}, \mathrm{N}^{\mathrm{m}}, \mathrm{O}^{\mathrm{m}}$ and $\mathrm{Q}^{\mathrm{m}}$ denotes the coefficient of fuel cost of $\mathrm{m}^{\text {th }} \mathrm{GU}, \mathrm{P}_{\mathrm{min}}^{\mathrm{Gm}}$ indicates the minimum active power output of the $\mathrm{m}^{\text {th }} \mathrm{GU}$ and $\mathrm{j}^{\mathrm{w}}$ refers to the fuel cost coefficient of $\mathrm{w}^{\text {th }} \mathrm{WT}$ system.

$$
\mathrm{F}\left(\mathrm{P}^{\mathrm{gm}}\right)=\sum_{\mathrm{m}=1}^{\mathrm{S}}\left[\mathrm{K}^{\mathrm{m}}+\mathrm{L}^{\mathrm{m}} \mathrm{P}^{\mathrm{gm}}+\mathrm{N}^{\mathrm{m}}\left(\mathrm{P}^{\mathrm{gm}}\right)^{2}+\mid \mathrm{O}^{\mathrm{m}} \sin \left\{\mathrm{Q}^{\mathrm{m}}\left(\mathrm{P}_{\text {min }}^{\mathrm{gm}} \mathrm{P}^{\mathrm{gm}}\right)\right)\right]+\sum_{\mathrm{w}=1}^{\mathrm{T}} \mathrm{j}^{\mathrm{w}} \mathrm{e}^{\mathrm{w}}
$$

Emission Model: The thermal power plant usually emits $\mathrm{NO}_{\mathrm{x}}$ or $\mathrm{SO}_{2}$ as emissions owing to the fuel burning. Here, only $\mathrm{NO}_{\mathrm{x}}$ are regarded as emissions. Consequently, the integration of the quadratic function subsequent to the exponential function produces the necessary emission function that is given in Eq. (4). In the particular equation, $\mathrm{U}^{\mathrm{m}}, \mathrm{Z}^{\mathrm{m}}, \mathrm{W}^{\mathrm{m}}, \mathrm{X}^{\mathrm{m}}$ and $\mathrm{Y}^{\mathrm{m}}$ point out the emission coefficient regarding $\mathrm{m}^{\text {th }} \mathrm{GU}$. Nevertheless, the coefficients $\alpha^{\mathrm{m}}$ and $\lambda^{\mathrm{m}}$ can be exploited only when the system is linked with the VPE.

$$
\mathrm{e}\left(\mathrm{P}^{\mathrm{gm}}\right)=\sum_{\mathrm{m}=1}^{\mathrm{S}} \mathrm{U}^{\mathrm{m}}+\mathrm{Z}^{\mathrm{m}} \mathrm{P}^{\mathrm{gm}}+\mathrm{W}^{\mathrm{m}}\left(\mathrm{P}^{\mathrm{gm}}\right)^{2}+\mathrm{X}^{\mathrm{m}} \exp \left(\mathrm{Y}^{\mathrm{m}} \mathrm{P}^{\mathrm{gm}}\right)
$$

Power Balancing Model: Concerning the reduction process, it is essential to gratify some inequality and equality factors. The equality constraint can in addition be known as power balance, since it produces the entire power that must distribute the entire power demand and entire power loss in the network. The operation of power balancing representation is given by Eq. (5) in which $\mathrm{P}^{\text {ld }}$ indicates the entire load demand and $\mathrm{P}^{\text {loss }}$ denotes the active power loss in the network. Accordingly, the configuration of $\mathrm{P}^{\text {loss }}$ is specified in Eq. (6) in which $\mathrm{C}_{\mathrm{mn}}$ denotes the loss coefficient between $\mathrm{m}^{\text {th }}$ and $\mathrm{n}^{\text {th }}$ GU's.

$$
\begin{aligned}
& \sum_{\mathrm{m}=1}^{\mathrm{S}} \mathrm{P}^{\mathrm{gm}}-\mathrm{P}^{\mathrm{ld}}-\mathrm{P}^{\mathrm{loss}}=0 \\
& \mathrm{P}^{\mathrm{loss}}=\sum_{\mathrm{m}=1}^{\mathrm{N}} \sum_{\mathrm{n}}^{\mathrm{N}} \mathrm{P}^{\mathrm{gm}} \mathrm{C}_{\mathrm{mn}} \mathrm{P}^{\mathrm{gn}}
\end{aligned}
$$

\subsection{0bjective Model}

The permutation of two self-reliant intentions can capable to resolve the CEED crisis [5]. Those intentions are related with the emission cost and fuel cost. Consequently, a single intention is produced from which the abovementioned costs are produced from the bi-objective function, by means of a penalty parameter. Therefore, with the intention of resolving the CEED crisis, it is required to minimize the cost of fuel in addition to emission cost. Eq. (7) configures the reduction of CEED crisis as a single objective function, in which $f_{p}$ refers the penalty parameter which is specified in Eq. (9), in which $\mathrm{P}_{\max }^{\mathrm{gm}}$ and $\mathrm{P}_{\min }^{\mathrm{gm}}$ indicates the maximum and minimum active power output.

$$
\begin{aligned}
& \operatorname{Minimize}\left(\mathrm{F}^{\mathrm{CEED}}\right)=\mathrm{F}+\mathrm{f}_{\mathrm{p}} \mathrm{E}
\end{aligned}
$$

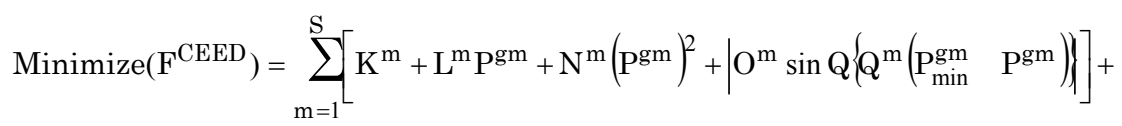

$$
\begin{aligned}
& \sum_{\mathrm{w}=1}^{\mathrm{T}} \frac{\mathrm{P}_{0} \mathrm{aV}_{\mathrm{w}}^{3} \mathrm{~K}^{\mathrm{p}}}{2 \mathrm{~g}_{\mathrm{k}} \mathrm{t}} \mathrm{e}^{\frac{\mathrm{GH}}{\mathrm{g}_{\mathrm{k}} \mathrm{t}}}+\mathrm{f}_{\mathrm{p}}\left(\sum_{\mathrm{m}=1}^{\mathrm{S}} \mathrm{U}^{\mathrm{m}}+\mathrm{V}^{\mathrm{m}} \mathrm{P}^{\mathrm{gm}}+\mathrm{w}^{\mathrm{m}}\left(\mathrm{P}^{\mathrm{gm}}\right)^{2}+\mathrm{x}^{\mathrm{m}} \exp \left(\mathrm{Y}^{\mathrm{m}} \mathrm{P}^{\mathrm{gm}}\right)\right)
\end{aligned}
$$




$$
\begin{aligned}
& f_{p}=\frac{F\left(P_{\text {max }}^{G m}\right)}{e\left(P_{\text {max }}^{G m}\right)} \\
& f_{p}=\frac{K^{m}+L^{m} P_{\text {max }}^{G m}+N^{m}\left(P_{\text {max }}^{G m}\right)^{2}+O^{m} \sin \left\{Q^{m}\left(P_{\text {min }}^{g m} \quad P_{\text {max }}^{G m}\right)\right\}}{U^{m}+V^{m} P_{\text {max }}^{G m}+W^{m}\left(P_{\max }^{G m}\right)^{2}+x^{m} \exp \left(Y^{m} P_{\max }^{G m}\right)}
\end{aligned}
$$

\subsection{Solution Encoding}

Since the thermal power plant could not minimize the emission cost and fuel cost in HRES system, it is elaborated with the wind turbine connection. The solution pattern of all fireflies is revealed in fig. 2 . Accordingly, for each firefly, the solution is illustrated with respect to wind turbine and thermal power plant. In addition, the best possible hybrid renewable energy systems are obtained by the noteworthy assessment and update of each FF algorithm.

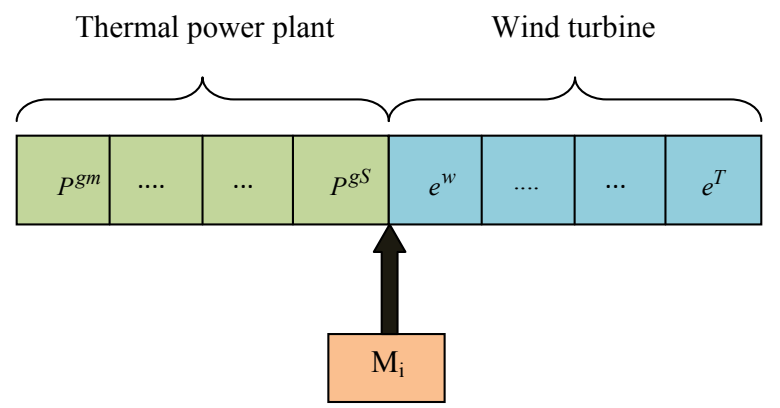

Fig. 1. Solution encoding for each firefly

\subsection{Firefly Algorithm}

The major feature of fireflies is their flashing light. These lights include two fundamental characteristics [19]. Initial one is to attract mating partners and subsequent one is to warn the predators. The flashing light includes more physical norms. In addition, the distance wraises as the light intensity I lessens as shown by Eq. (11)

$$
\operatorname{Ia} \frac{1}{\mathrm{w}^{2}}
$$

Two fundamental crises have to be resolved for designing the FF algorithm precisely. They are the attraction formulation and the variations in light intensity. In standard FF algorithm, light intensity I denoting the solution $S$ is comparative to the fitness value. Further, the intensity of light $\mathrm{I}(\mathrm{w})$ varies depending on Eq. (12), where $\mathrm{I}_{0}$ denotes the intensity of light attained from the source, and the absorption of light is calculated by the deployment of light absorption coefficient $\gamma$.

$$
I(w)=I_{0} e^{-\gamma w^{2}}
$$

The equivalence at $\mathrm{w}=0$ in $\mathrm{I}=\mathrm{w}^{2}$ is banned by fusing the inverse square law effects and an presumption of absorption in the kind of Gaussian. The attractiveness of fireflies is specified by $\beta$ that is proportional to their intensity of light $\mathrm{I}(\mathrm{w})$. As a result Eq. (13) similar as Eq. (11) can be specified, to portray the attractiveness, $\beta$, in which $\beta_{0}$ is the attraction level at $w=0$. The attractiveness $\beta$ and intensity of light I are approximately similar in particular circumstances. The light created by the firefly is the appropriate assessment of light intensity and attraction can be designed on the basis of the related evaluation and subsequently they are predestined by other fireflies.

$$
\beta=\beta_{0} \mathrm{e}^{-\gamma \mathrm{w}^{2}}
$$

The distance sandwiched between two fireflies $M_{i}$ and $M_{j}$ is specified in Eq. (14), in which $n$ specifies the dimensionality inconveniences. The mobility of the $i^{\text {th }}$ firefly is indented by other firefly $j$ which is more stunning. 


$$
\mathrm{w}_{\mathrm{ij}}=\left\|\mathrm{M}_{\mathrm{i}}-\mathrm{M}_{\mathrm{j}}\right\|=\sqrt{\sum_{\mathrm{k}=1}^{\mathrm{k}=\mathrm{n}}\left(\mathrm{M}_{\mathrm{ik}}-\mathrm{M}_{\mathrm{jk}}\right)^{2}}
$$

In this manner, the specified equation can be deployed as exposed in Eq. (15) in which $\varepsilon_{i}$ is an arbitrary number attained from Gaussian distribution. The movement of fireflies comprises of three parameters, the current location of $i^{\text {th }}$ firefly, attractiveness in the path of more attractive fireflies, and a arbitrary walk that comprises a term known as $\alpha$ and the arbitrarily generated integer lying between 0 and 1 . When $\beta_{0}=0$, the movement is dependent on the walks which are arbitrary. The term $\gamma$ has a huge manoeuvring on the speed of convergence. Yet the $\gamma$ value can attain any integer ranging among $\gamma \in[0, \infty]$; its creation is dependent on the crisis that should be optimized. Generally, it lies between 0.1to10.

$$
\mathrm{M}_{\mathrm{i}}=\mathrm{M}_{\mathrm{i}}+\beta_{0} \mathrm{e}^{-\gamma \mathrm{wij}^{2}}\left(\mathrm{M}_{\mathrm{j}}-\mathrm{M}_{\mathrm{i}}\right)+\alpha \varepsilon_{\mathrm{i}}
$$

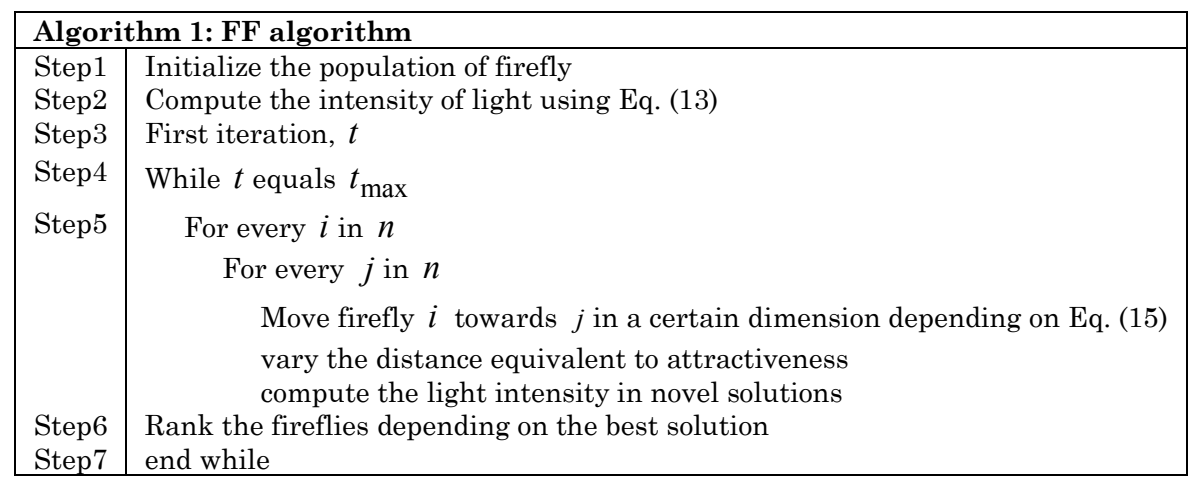

\section{Results and Discussions}

\subsection{Simulation Procedure}

The experimentation concerning the minimization of CEED crisis was deployed in seven HRES test bus systems. These systems are comprehensively exploited as benchmarks in the field of electrical power systems for the intention of CEED crisis minimization, which therefore have been utilized by numerous research groups all over the world. Moreover, the proposed FF-HRES scheme was compared with SA [20] and DE algorithms [21] and the results were attained.

\subsection{Convergence Analysis}

The convergence analysis for the reduction of CEED crisis is given by Fig. 2 for seven HRES test systems. From Fig. 2(a), the proposed scheme for $0^{\text {th }}$ iteration is $3.58 \%$ better than SA and $1.67 \%$ better than DE methods. Similarly, the suggested method for $200^{\text {th }}$ iteration is $1.38 \%$ superior to SA and $0.83 \%$ superior to DE schemes. In addition, the proposed method for $400^{\text {th }}$ iteration is $1.39 \%$ better than SA and $0.83 \%$ better than DE methods. Moreover, for $600^{\text {th }}$ iteration, the suggested scheme is $1.9 \%$ superior to SA and 1.4\% superior to DE schemes. Similarly, from Fig. 2(b), the implemented method for $0^{\text {th }}$ iteration is $4.95 \%$ better than SA and $1.92 \%$ better than DE methods. Similarly, the suggested method for $200^{\text {th }}$ iteration is $4.98 \%$ superior to SA and $3.6 \%$ superior to DE schemes. Also, from Fig. 2(c), the proposed scheme for $0^{\text {th }}$ iteration is $3.3 \%$ better than SA and $2.47 \%$ better than DE methods. Similarly, the suggested method for $200^{\text {th }}$ iteration is $1.64 \%$ superior to $\mathrm{SA}$ and $1.36 \%$ superior to $\mathrm{DE}$ schemes. Moreover, from Fig. 2(d), the presented method for $0^{\text {th }}$ iteration is $3.3 \%$ better than SA and $2.47 \%$ better than DE methods. Likewise, the suggested method for $200^{\text {th }}$ iteration is $0.1 \%$ superior to SA and $2.53 \%$ better than DE techniques. In addition, from Fig. 2(e), the proposed method for $400^{\text {th }}$ iteration is $0.85 \%$ better than SA and $0.67 \%$ better than DE methods. Moreover, for $600^{\text {th }}$ iteration, the suggested scheme is $0.9 \%$ superior to SA and $0.81 \%$ superior to DE schemes. Also, from Fig. $2(\mathrm{f})$, the implemented method for $0^{\text {th }}$ iteration is $9.5 \%$ better than SA and $6 \%$ better than DE methods. Similarly, the suggested method for $200^{\text {th }}$ iteration is $4 \%$ superior to $\mathrm{SA}$ and $3.35 \%$ superior to DE schemes. Finally, from Fig. 2(g), the presented scheme for $400^{\text {th }}$ iteration is $0.64 \%$ better than SA and $0.53 \%$ better than DE methods. Moreover, for $600^{\text {th }}$ iteration, the suggested scheme is $0.67 \%$ superior to $\mathrm{SA}$ and $0.6 \%$ superior to $\mathrm{DE}$ schemes. Thus from the convergence analysis, the capability of the implemented FF-HRES method has been validated efficiently. 


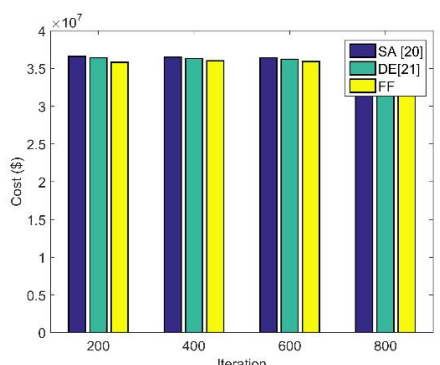

(a)

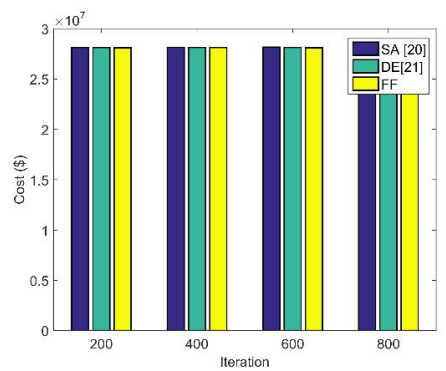

(d)

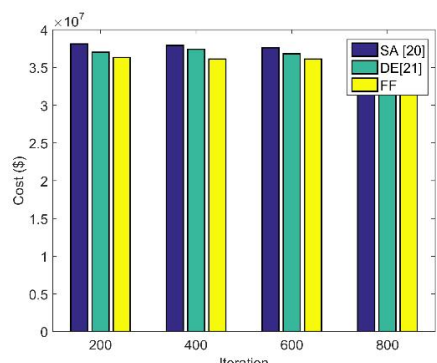

(b)

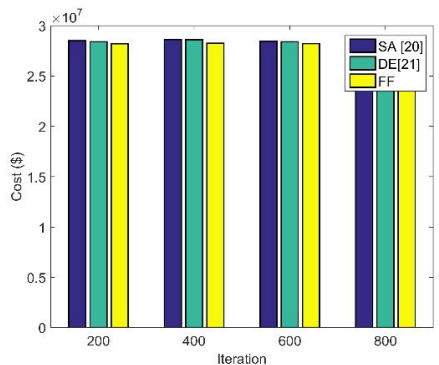

(e)

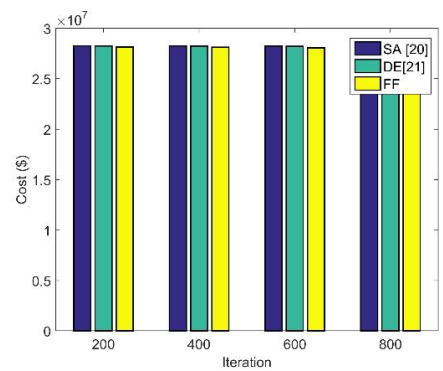

(g)

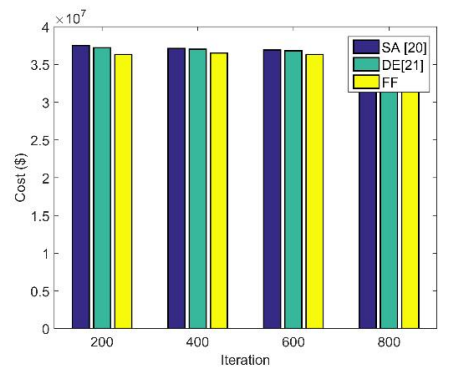

(c)

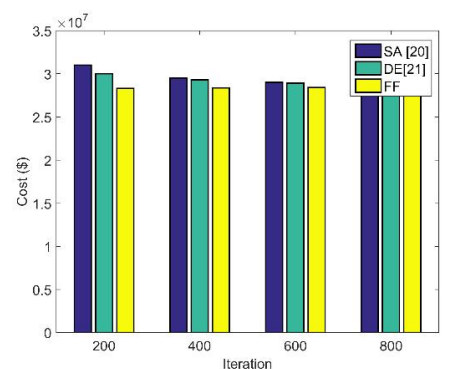

(f)

Fig. 2. Convergence analysis for (a) Test case1 (b) Test case 2 (c) Test case 3 (d) Test case 4 (e) Test case 5 (f) Test case 6 (g) Test case 7

\section{Conclusion}

This paper has presented the analysis which adopts the CEED formulation in the power system. Consequently, it has merged the thermal power plant and wind turbine to enhance the execution of CEED. For discovering the solutions of the CEED issues, this paper has implemented the FF algorithm that was executed in seven HRES test bus systems. Moreover, the proposed FF-HRES method was compared with conventional SA and DE algorithms and the results were obtained. From the analysis, the proposed scheme for $0^{\text {th }}$ iteration is $3.58 \%$ superior to SA and $1.67 \%$ superior to DE methods. Similarly, the suggested method for $200^{\text {th }}$ iteration is $1.38 \%$ better than SA and $0.83 \%$ better than DE schemes. In addition, the proposed method for $400^{\text {th }}$ iteration is $1.39 \%$ better than SA and $0.83 \%$ better than DE methods. Moreover, for $600^{\text {th }}$ iteration, the suggested scheme is $1.9 \%$ superior to SA and $1.4 \%$ superior to DE schemes.

\section{Compliance with Ethical Standards}

Conflicts of interest: Authors declared that they have no conflict of interest.

Human participants: The conducted research follows the ethical standards and the authors ensured that they have not conducted any studies with human participants or animals.

\section{References}

[1] Karl Mason, Jim Duggan, Enda Howley, "Multi-objective dynamic economic emission dispatch using particle swarm optimisation variants", Neurocomputing, vol. 270, pp. 188-197, 27 December 2017. 
[2] Tiancai Wang, Xing He, Tingwen Huang, Chuandong Li, Wei Zhang, "Collective neurodynamic optimization for economic emission dispatch problem considering valve point effect in microgrid”, Neural Networks, vol. 93, pp. 126-136, September 2017.

[3] Vinay Kumar Jadoun, Nikhil Gupta, K.R. Niazi, Anil Swarnkar, "Modulated particle swarm optimization for economic emission dispatch", International Journal of Electrical Power \& Energy Systems, vol. 73, pp. 80-88, December 2015.

[4] Abhishek Rajan, T. Malakar, "Optimum economic and emission dispatch using exchange market algorithm", International Journal of Electrical Power \& Energy Systems, vol. 82, pp. 545-560, November 2016.

[5] A.Y. Abdelaziz, E.S. Ali, S.M. Abd Elazim, "Combined economic and emission dispatch solution using Flower Pollination Algorithm”, International Journal of Electrical Power \& Energy Systems, vol. 80, pp. 264-274, September 2016.

[6] Fahad Parvez Mahdi, Pandian Vasant, Vish Kallimani, Junzo Watada, M. Abdullah-Al-Wadud, "A holistic review on optimization strategies for combined economic emission dispatch problem", Renewable and Sustainable Energy Reviews, vol. 81, Part 2, pp. 3006-3020, January 2018.

[7] Haiping Ma, Zhile Yang, Pengcheng You, Minrui Fei, "Multi-objective biogeography-based optimization for dynamic economic emission load dispatch considering plug-in electric vehicles charging”, Energy, vol. 135, pp. 101-111, 15 September 2017.

[8] Abdirahman Mohamed Abdilahi, Mohd Wazir Mustafa, "Carbon capture power plants: Decoupled emission and generation outputs for economic dispatch", International Journal of Greenhouse Gas Control, vol. 63, pp. 12-19, August 2017.

[9] A.Y. Abdelaziz, E.S. Ali, S.M. Abd Elazim, "Flower pollination algorithm to solve combined economic and emission dispatch problems", Engineering Science and Technology, an International Journal, vol. 19, no. 2, pp. 980-990, June 2016.

[10] Lahouaria Benasla, Abderrahim Belmadani, Mostefa Rahli, "Spiral Optimization Algorithm for solving Combined Economic and Emission Dispatch", International Journal of Electrical Power \& Energy Systems, vol. 62, pp. 163-174, November 2014.

[11] A.Y. Abdelaziz, E.S. Ali, S.M. Abd Elazim, "Implementation of flower pollination algorithm for solving economic load dispatch and combined economic emission dispatch problems in power systems", Energy, vol. 101, pp. 506518, 15 April 2016.

[12] Dexuan Zou, Steven Li, Zongyan Li, Xiangyong Kong, "A new global particle swarm optimization for the economic emission dispatch with or without transmission losses”, Energy Conversion and Management, vol. 139, pp. 45-70, 1 May 2017.

[13] M.H. Alham, M. Elshahed, Doaa Khalil Ibrahim, Essam El Din Abo El Zahab, "A dynamic economic emission dispatch considering wind power uncertainty incorporating energy storage system and demand side management", Renewable Energy, vol. 96, Part A, pp. 800-811, October 2016.

[14] Mostafa Modiri-Delshad, Nasrudin Abd Rahim, "Multi-objective backtracking search algorithm for economic emission dispatch problem", Applied Soft Computing, vol. 40, pp. 479-494, March 2016.

[15] A.M. Jubril, O.A. Olaniyan, O.A. Komolafe, P.O. Ogunbona, "Economic-emission dispatch problem: A semidefinite programming approach”, Applied Energy, vol. 134, pp. 446-455, 1 December 2014.

[16] M. Basu, "Fuel constrained economic emission dispatch using non dominated sorting genetic algorithm-II", Energy, vol. 78, pp. 649-664, 15 December 2014.

[17] C. Palanichamy, N. Sundar Babu, "Analytical solution for combined economic and emissions dispatch", Electric Power Systems Research, vol. 78, no. 7, pp. 1129-1137, July 2008.

[18] C. Shilaja, K. Ravi, "Optimization of emission/economic dispatch using euclidean affine flower pollination algorithm (eFPA) and binary FPA (BFPA) in solar photo voltaic generation”, Renewable Energy, vol. 107, pp. 550-566, July 2017.

[19] Iztok Fister, Iztok Fister, Xin-She Yang, Janez Brest, "A comprehensive review of firefly algorithms", Swarm and Evolutionary Computation, Vol. 13, pp. 34-46, December 2013.

[20] Madson L. Dantas Dias, Ajalmar R. Rocha Neto, "Training soft margin support vector machines by simulated annealing: A dual approach”, Expert Systems with Applications, vol. 87, pp. 157-169, 30 November 2017.

[21] Guohua Wu, Xin Shen, Haifeng Li, Huangke Chen, P.N. Suganthan, "Ensemble of differential evolution variants", Information Sciences, vol. 423, pp. 172-186, January 2018. 